\title{
PREPARATION, CHARACTERIZATION AND IN-VITRO RELEASE OF CONTROLLED RELEASE KETOROLAC TROMETHAMINE CELLULOSE ACETATE BUTYRATE MICROSPHERES
}

\author{
S. Abd El-Rasoul* and Mahmoud M. Ahmed
}

Department of Pharmaceutics and Industrial Pharmacy, Faculty of Pharmacy, Al-Azhar University, Assiut branch, Assiut, Egypt

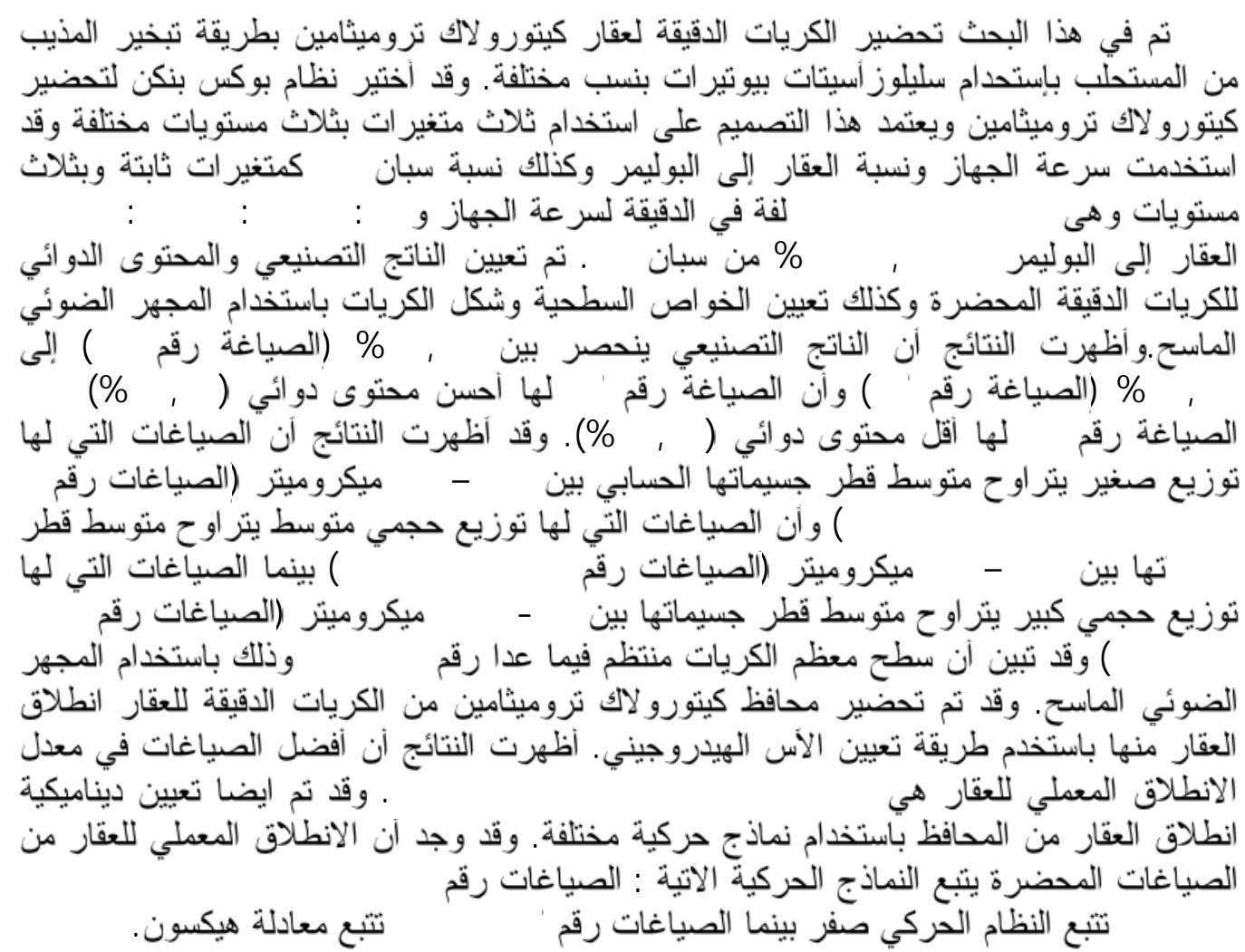

The purpose of this study was to prepare and characterize controlled release ketorolac tromethamine microspheres. To achieve this goal, cellulose acetate butyrate microspheres loaded by ketorolac tromethamine were prepared by the emulsion solvent evaporation method.

The prepared ketorolac tromethamine microspheres were evaluated for their production yields, particle size distribution, morphology, drug content and drug release characteristics. Thermal Gravimetric Analysis (TGA) were performed on the drug polymer systems in order to shed a light on the possibility of solid state changes of ketorolac tromethamine with $C A B$.

A Box-Behnken design was selected for formulating ketorolac tromethamine microspheres with revolution per minute (X1), drug-polymer ratio (X2) and span 80 percent (X3) as independent variables. Three levels of the independent variables were used which equal to -1, 0 and +1 for the above design. The values of the corresponding variables were 500, 700 and 900 rpm for the machine speed; $1: 1,1: 2$ and 1:3 for drug-polymer ratio; $1 \%, 1.5 \%$ and $2 \%(w / w)$ for span 80 percent. 


\section{INTRODUCTION}

Ketorolac tromethamine is a potent analgesic, anti-inflammatory drug. It is one of the few NSAIDs approved for parenteral administration. On the basis of animals studies it appears to have relatively more pronounced analgesic activity than most NSAIDS ${ }^{1}$. In the mouse writhing assay, it was found to be 350 times more potent as an analgesic than aspirin, on weight basis, 50 times as potent as naproxen, and six times as potent as indomethacin $^{2}$. The biological half life of ketorolac is quoted to be $5.4 \mathrm{hrs}$ with a range of 4.5-5.6 hrs which makes it suitable to be designed as a controlled release formulation.
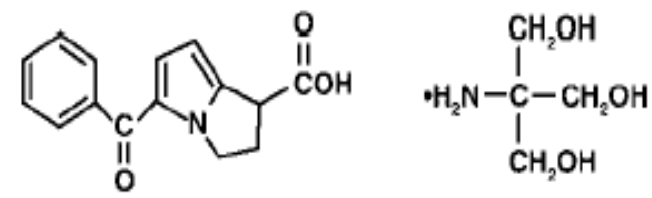

(士)-1H-Pyrrolizine-1-carboxylicacid,5-benzoyl-2,3dihydro-compound with 2-amino-2 hydroxy- methyl1,3-propanediol.

Microspheres have been widely accepted as a means to achieve oral ${ }^{3}$ and parentral controlled release drug delivery system ${ }^{4}$. The microspheres require a polymeric substance as a carrier and a core material. Among various methods developed for formulation of microspheres, the emulsion solvent evaporation method has gained much attention due to its ease of fabrication without compromising the activity of drug. In the present investigation, Cellulose acetate butyrate was used as encapsulating materials. Box-Behnken design was used for formulating ketorolac tromethamine cellulose acetate microspheres ${ }^{5}$. It deals with, optimization of formulation variables to improve the in-vitro release of ketorolac tromethamine dosage forms. Microspheres were prepared by emulsion solvent evaporation technique ${ }^{6-8}$. Cellulose esters widely used to impart controlled release properties to many drugs?

The main purpose of present research was to develop a controlled drug delivery system of ketorolac tromethamine for oral administration using cellulose acetate butyrate as a polymer via emulsion solvent evaporation technique applying Box-Behnken design to choose these formulae.

\section{EXPERIMENTAL}

\section{Materials}

Ketorolac Tromethamine (KT), El-Kahira Pharm. Chem. Co., (Cairo, Egypt). Cellulose Acetate Butyrate (CAB), Sigma Chem. Co., St. Louis (USA). Span 80, Sigma Chem. Co., Stoneham (Germany). Acetone, El-Nasr Pharm. Chem. Co., Cairo (Egypt). Liquid Paraffin, ElGomhoria Chem. Co., Cairo (Egypt). Magnesium Stearate, El-Gomhoria Chem. Co., Cairo (Egypt). Hydrochloric acid, Potassium dihydrogen orthophosphate, disodium hydrogen phosphate, Sodium chloride and sodium hydroxide, El-Nasr Pharm. Co., Cairo (Egypt). n-hexane, El-Nasr Pharm. Co., Cairo (Egypt). Cyclohexan, Sigma Chem. Co., Stoneham (Germany). All the other reagents were analytical grade and were used recieved.

\section{Methods \\ Design of the experiment}

A Box-Behnken design was selected for formulating ketorolac tromethamine microspheres with revolution per minute (X1), drugpolymer ratio (X2) and span 80 percent (X3) as independent variables. Three levels of the independent variables were used which equal to $-1,0$ and +1 for the above design. The values of the corresponding variable were 500, 700 and $900 \mathrm{rpm}$ for the machine speed; 1:1, 1:2 and 1:3 for drug-polymer ratio and $1 \%, 1.5 \%$ and $2 \%(\mathrm{w} / \mathrm{w})$ for span 80 percent.

\section{Preparation of ketorolac tromethamine - cellulose acetate butyrate $(\mathrm{CAB})$ micro- particles by emulsion solvent evaporation (w/o) technique}

Ketorolac tromethamine was dispersed in the polymeric solution of cellulose acetate butyrate which dissolved in $(25 \mathrm{ml})$ acetone forming the internal phase. The drug-polymer ratios 1:1, 1:2 and 1:3. Known amount of magnesium stearate $(125 \mathrm{mg})$ was dispersed in the different internal phases as soothing agent. This dispersion was added drop wise to liquid paraffin (external phase) $(150 \mathrm{ml})$ containing different concentrations of span 80 as emulsifying agent and was emulsified by stirring at different speeds. The stirring was continued at room temperature until complete evaporation of the solvent (acetone) about 5-7 hrs. 
Liquid paraffin was decanted and the microspheres produced were filtered off, washed three times with n-hexane and three times with cyclohexane to remove the remaining oily phase and then dried overnight at room temperature.

\section{Yield determination}

The yield of the microspheres was determined by dividing the weight of the prepared microparticles by the original amount of the polymer and drug used. The results were expressed as a percentage.

\section{Particle size determination}

The dried microspheres were weighed and sized using USP standard sieve set. The fraction of microspheres remaining on each sieve was collected, and the mean particle size of the microspheres was determined as the percentage of microspheres retained at each sieve multiplied by the average particle size of this sieve.

\section{Determination of drug content}

The drug content of the prepared ketorolac tromethamine microspheres was determined by the following method ${ }^{9}$.

\section{Digestion method}

One hundred $\mathrm{mg}$ of ketorolac tromethamine microparticles were crushed carefully in a glass mortar and transferred to a $100 \mathrm{ml}$ volumetric flask using phosphate buffer $\mathrm{pH}$ 7.4. The volumetric flask was completed to the volume with phosphate buffer $\mathrm{pH} 7.4$ then agitated for 5 min. each hour for 5 hrs. The sample was filtered and the drug concentration was determined specrophotometerically at 325 $\mathrm{nm}$. The same procedure was applied for the plain formula, which was used as a blank. The concentration was calculated using the standard calibration curve of ketorolac tromethamine in phosphate buffer $\mathrm{pH} 7.4$.

\section{Photo-micrograph of ketorolac trome- thamine microspheres}

Diluted suspension of ketorolac tromethamine microspheres in liquid paraffin was mounted on a slide. A photograph for each microsphere was taken from the prepared slide at magnification powers 40 and 100x.

\section{Thermal gravimetric analysis (TGA)}

TGA studies were carried out using previously prepared Ketorolac Tromethamine microspheres with drug to polymer ratio 1:1 and the corresponding physical mixtures as well as, drug alone in order to determine the extent of crystallinity of the drug in the presence of the studied polymers and to examine any possible interaction between Ketorolac Tromethamine and the used polymers. Samples were placed in an aluminum pan and heated at a rate of $10^{\circ} \mathrm{C} / \mathrm{min}$ with indium in the reference pan, in an atmosphere of nitrogen up to $280^{\circ} \mathrm{C}$.

\section{Preparation of capsules}

An appropriate amount of ketorolac tromethamine microspheres (prepared from Cellulose acetate butyrate) equivalent to $30 \mathrm{mg}$ of ketorolac tromethamine was filled into hard gelatin capsules No.2.

\section{In-vitro release of ketorolac tromethamine capsules}

Dissolution testing of the prepared microspheres equivalent to $30 \mathrm{mg}$ of ketorolac tromethamine was performed with the rotating basket apparatus according to USP XXIV apparatus 2. Hard gelatin capsules No.2 filled with known amount of microparticles. The operating conditions were: Basket speed of 50 rpm and a temperature of $37^{\circ} \mathrm{C} \pm 0.5$, regarding the dissolution medium, the $\mathrm{pH}$ shift method $^{10-12}$.

First, $500 \mathrm{ml}$ of $0.1 \mathrm{~N} \mathrm{HCl} \mathrm{pH} \mathrm{1.2,} \mathrm{was}$ used as the release medium for two hours, followed by the addition of (5.7) $\mathrm{ml}$ of $7 \mathrm{~m}$ $\mathrm{KH}_{2} \mathrm{PO}_{4}$ containing $16.75 \%(\mathrm{w} / \mathrm{v}) \mathrm{NaOH}$ in order to change the $\mathrm{pH}$ of the medium to 7.4 and the experiment was continued for another six hours. Filtered samples, $3 \mathrm{ml}$ each, were removed at $0.25,0.5,1,1.5,2,2.25,2.5,3,4$, 5, 6, 7 and 8 hrs. The samples were diluted appropriately with the release medium, and absorbance was measured at the predetermined $\lambda_{\max }$ of each medium against a blank of this medium. The withdrawn samples were replaced with equal volumes of the release medium kept at $37^{\circ} \mathrm{C}$. 


\section{Kinetics of the in-vitro release of ketorolac tromethamine capsules}

The kinetic parameters for the in-vitro release of ketorolac tromethamine were determined and then analyzed in order to find the proper order of the drug release using a specific computer program. Zero-, first-, and second order kinetic, as well as controlled diffusion model ${ }^{13}$. Hixson-Crowell cup root law and Baker-Lonsdale equation were investigated $^{14 \& 15}$.

\section{RESULTS AND DISCUSSION}

Box-Behnken design, as shown in table 1, was used for formulating ketorolac tromethamine cellulose acetate microparticles ${ }^{5}$. It deals with, optimization of formulation variables to improve the in-vitro release of ketorolac tromethamine dosage forms.

Different concentrations of $\mathrm{CAB}$ were tried in this work, i.e, 2, 4, 6 and $8 \%$. Both $2 \%$ and $4 \% \mathrm{CAB}$ gave non spherical microparticles while $8 \%$ and more gave hard sheets of $\mathrm{CAB}$. So, $6 \%$ CAB was used in this study.

Cellulose acetate butyrate containing ondanstron or butesonide were prepared by the emulsion-solvent evaporation method in an oily phase. Mixture of acetone and methanol in proper ratio $(2: 1 \mathrm{v} / \mathrm{v}, 3 \mathrm{ml})$ which was found to be excellent solvent for dissolving both drugs and polymers, polymer concentrations studied were 4,6 and $8 \%$ and the drug polymer ratio was $1: 10$. The emulsified used was $1 \%$ of span 85 into liquid paraffin $(70 \mathrm{ml})$ and $0.1 \%(\mathrm{w} / \mathrm{w})$ of antifoam? ${ }^{9}$.

Magnesium stearate was added to the formulations as droplet stabilizer to overcome problem of droplet coalescence during solvent evaporation ${ }^{16}$. The action of magnesium stearate as soothing agent and liquid paraffin as external phase were used as a part of the emulsion solvent evaporation technique while the surfactant (span 80) was used as emulsifying agent.

\section{Production yield determination}

The range of the production yield of the prepared ketorolac tromethamine $\mathrm{CAB}$ microspheres was found to be between $79.55 \%$ and $94.61 \%$ as shown in table 2. These data were represented as histogram in figure 2.
The best value appeared in the formula F13 $(94.61 \%)$ while the worst value appeared in formula F11 (79.55\%).

\section{Drug content determination}

The drug content determination measures the actual weight of ketorolac tromethamine inside the $\mathrm{CAB}$ microspheres. The rank order of the drug content was measured by the deviation from the theoretical weight. Formula 13 gave the best drug content of the prepared ketorolac tromethamine microparticles (77.12\%), while formula F11 showed the worst value $(51.90 \%)$ as shown in table 2 and illustrated as histogram in figure 1.

\section{Particle size distribution}

Table 3 shows the fraction percent of weight distribution of different formulae of ketorolac tromethamine $\mathrm{CAB}$ microspheres determined by sieve analysis. Formulae F4, F7, F8, F9, F10, F11, and F15 exhibit the best distribution pattern as the largest weight determined lied between 315-200 $\mu \mathrm{m}$, while formulae F2, F3, F13 and F14 gave the second group of good distribution as a largest weight calculated lied between 400-315 $\mu \mathrm{m}$. The remaining formulae F1, F5, F6 and F12 exhibit high distribution as the largest weight determined lied between $(890-630 \mu \mathrm{m})$.

So, the formulated ketorolac tromethamine microspheres were arranged according to the mean particle size, in a descending order, as the following: F1, F12, F6, F5, F2, F13, F3, F14, F7, F8, F9, F4, F10 F11 and F15. Speed is the maximum parameters for controlling the drug/matrix dispersion's droplet size in the continues phase. It was shown that increasing the mixing speed generally results in decreased microsphere size, as it produces smaller emulsion droplets through stronger shear forces and increased turbulence ${ }^{17-20}$.

In our study high stirring speed (900 rpm) produced microspheres with small particle size while low stirring speed $(500 \mathrm{rpm})$ produced microspheres with large particle size. Similar results were obtained by Prongpaibul et al. ${ }^{21}$.

Various manufacturing parameters (apparatus design, type of stirrer, stirring speed, viscosity of emulsion phase, polymer concentration and emulsifier concentration) affect particle size of the prepared microspheres $^{22 \& 23}$. 
Table 1: Composition of different suggested formulae of ketorolac tromethamine microparticles using cellulose acetate butyrate.

\begin{tabular}{|c|c|c|c|c|c|c|c||}
\hline $\begin{array}{c}\text { Formula } \\
\text { No. }\end{array}$ & $\begin{array}{c}\text { Drug } \\
(\mathrm{gm})\end{array}$ & $\begin{array}{c}\text { Cellulose acetate } \\
\text { butyrate } \\
(\mathrm{gm})\end{array}$ & $\begin{array}{c}\text { Magnesim } \\
\text { stearate } \\
(\mathrm{mg})\end{array}$ & $\begin{array}{c}\text { Liquid } \\
\text { paraffin } \\
\text { Ml }\end{array}$ & $\begin{array}{c}\text { Span } \\
80\end{array}$ & $\begin{array}{c}\text { Speed } \\
(\mathrm{rpm})\end{array}$ & $\begin{array}{c}\text { Total } \\
\text { weight } \\
(\mathrm{gm})\end{array}$ \\
\hline F1 & 1.5 & 1.5 & 125 & 150 & 2.25 & 500 & 3.125 \\
\hline F2 & 1.5 & 1.5 & 125 & 150 & 1.5 & 700 & 3.125 \\
\hline F3 & 1.5 & 1.5 & 125 & 150 & 3 & 700 & 3.125 \\
\hline F4 & 1.5 & 1.5 & 125 & 150 & 2.25 & 900 & 3.125 \\
\hline F5 & 0.75 & 1.5 & 125 & 150 & 1.5 & 500 & 2.375 \\
\hline F6 & 0.75 & 1.5 & 125 & 150 & 3 & 500 & 2.375 \\
\hline F7 & 0.75 & 1.5 & 125 & 150 & 2.25 & 700 & 2.375 \\
\hline F8 & 0.75 & 1.5 & 125 & 150 & 2.25 & 700 & 2.375 \\
\hline F9 & 0.75 & 1.5 & 125 & 150 & 2.25 & 700 & 2.375 \\
\hline F10 & 0.75 & 1.5 & 125 & 150 & 1.5 & 900 & 2.375 \\
\hline F11 & 0.75 & 1.5 & 125 & 150 & 3 & 900 & 2.375 \\
\hline F12 & 0.5 & 1.5 & 125 & 150 & 2.25 & 500 & 2.125 \\
\hline F13 & 0.5 & 1.5 & 125 & 150 & 1.5 & 700 & 2.125 \\
\hline F14 & 0.5 & 1.5 & 125 & 150 & 3 & 700 & 2.125 \\
\hline F15 & 0.5 & 1.5 & 125 & 150 & 2.25 & 900 & 2.125 \\
\hline
\end{tabular}

Independent variables

Level

\begin{tabular}{||l|l|l|l||}
\hline Speed & $+1=900$ & $0=700$ & $-1=500$ \\
\hline Drug-polymer ratio & $+1=1: 3$ & $0=1: 2$ & $-1=1: 1$ \\
\hline Span $80 \%$ & $+1=2 \%$ & $0=1.5 \%$ & $-1=1 \%$ \\
\hline
\end{tabular}

Table 2: Production yield (percentage recovery) and drug content (percentage drug loading) of ketorolac tromethamine - Cellulose acetate butyrate microspheres.

\begin{tabular}{|c|c|c|c|c|c|}
\hline $\begin{array}{c}\text { Formula } \\
\text { No. }\end{array}$ & $\begin{array}{c}\text { Drug polymer } \\
\text { ratio }\end{array}$ & $\begin{array}{c}\text { Production } \\
\text { yield } \\
\%\end{array}$ & $\begin{array}{c}\text { Theoretical } \\
\text { drug content } \\
(\mathrm{gm})\end{array}$ & $\begin{array}{c}\text { Actual drug } \\
\text { content } \\
(\mathrm{gm})\end{array}$ & $\begin{array}{c}\text { Drug content } \\
\%\end{array}$ \\
\hline F1 & $1: 1$ & 91.30 & 50.00 & 37.50 & 75.00 \\
\hline F2 & $1: 1$ & 91.00 & 50.00 & 35.05 & 70.10 \\
\hline F3 & $1: 1$ & 83.43 & 50.00 & 28.58 & 57.16 \\
\hline F4 & $1: 1$ & 81.32 & 50.00 & 27.16 & 54.32 \\
\hline F5 & $1: 2$ & 91.75 & 33.33 & 23.74 & 71.22 \\
\hline F6 & $1: 2$ & 86.52 & 33.33 & 19.43 & 58.29 \\
\hline F7 & $1: 2$ & 87.89 & 33.33 & 21.71 & 65.13 \\
\hline F8 & $1: 2$ & 90.35 & 33.33 & 23.15 & 69.46 \\
\hline F9 & $1: 2$ & 88.04 & 33.33 & 21.64 & 64.92 \\
\hline F10 & $1: 2$ & 88.80 & 33.33 & 21.51 & 64.53 \\
\hline F11 & $1: 2$ & 79.55 & 33.33 & 17.30 & 51.90 \\
\hline F12 & $1: 3$ & 82.57 & 25.00 & 13.03 & 52.12 \\
\hline F13 & $1: 3$ & 94.61 & 25.00 & 19.28 & 77.12 \\
\hline F14 & $1: 3$ & 81.79 & 25.00 & 13.26 & 53.04 \\
\hline F15 & $1: 3$ & 86.80 & 25.00 & 14.20 & 56.80 \\
\hline
\end{tabular}


Table 3: Sieve analysis of ketorolac tromethamine-cellulose acetate butyrate microparticles (F1).

Formula (1)

\begin{tabular}{|c|c|c|c|c|c||}
\hline $\begin{array}{c}\text { Sieve size } \\
(\mu)\end{array}$ & $\begin{array}{c}\text { Mean size } \\
(\mathrm{d})(\mathrm{m})\end{array}$ & $\begin{array}{c}\text { Weight } \\
\text { retained }(\mathrm{W})\end{array}$ & $\begin{array}{c}\% \text { Weight } \\
\text { retained } \\
(\% \mathrm{~W})\end{array}$ & $\begin{array}{c}\text { Cumulative } \\
\% \text { weight } \\
\text { retained }\end{array}$ & $\begin{array}{c}(\mathrm{d}) \mathrm{x} \\
(\% \mathrm{~W})\end{array}$ \\
\hline $890-630$ & 760 & 38.21 & 38.21 & 38.9898 & 29632.24 \\
\hline $630-400$ & 515 & 28.256 & 28.256 & 67.82245 & 14848.82 \\
\hline $400-315$ & 357.5 & 15.258 & 15.258 & 83.39184 & 5566.056 \\
\hline $315-200$ & 257.5 & 11.06 & 11.06 & 94.67755 & 2906.071 \\
\hline $200-160$ & 180 & 3.016 & 3.016 & 97.7551 & 553.9592 \\
\hline $160-100$ & 130 & 4.2 & 4.2 & 100 & 291.8367 \\
\hline Sum & 100 & 100 & & 53798.98 \\
\hline (dav) & 537.9898 & \multicolumn{5}{|l}{} \\
\hline
\end{tabular}

$\mathrm{d}_{\mathrm{av}}=$ Arithmetic mean diameter in $\mu \mathrm{m}$.

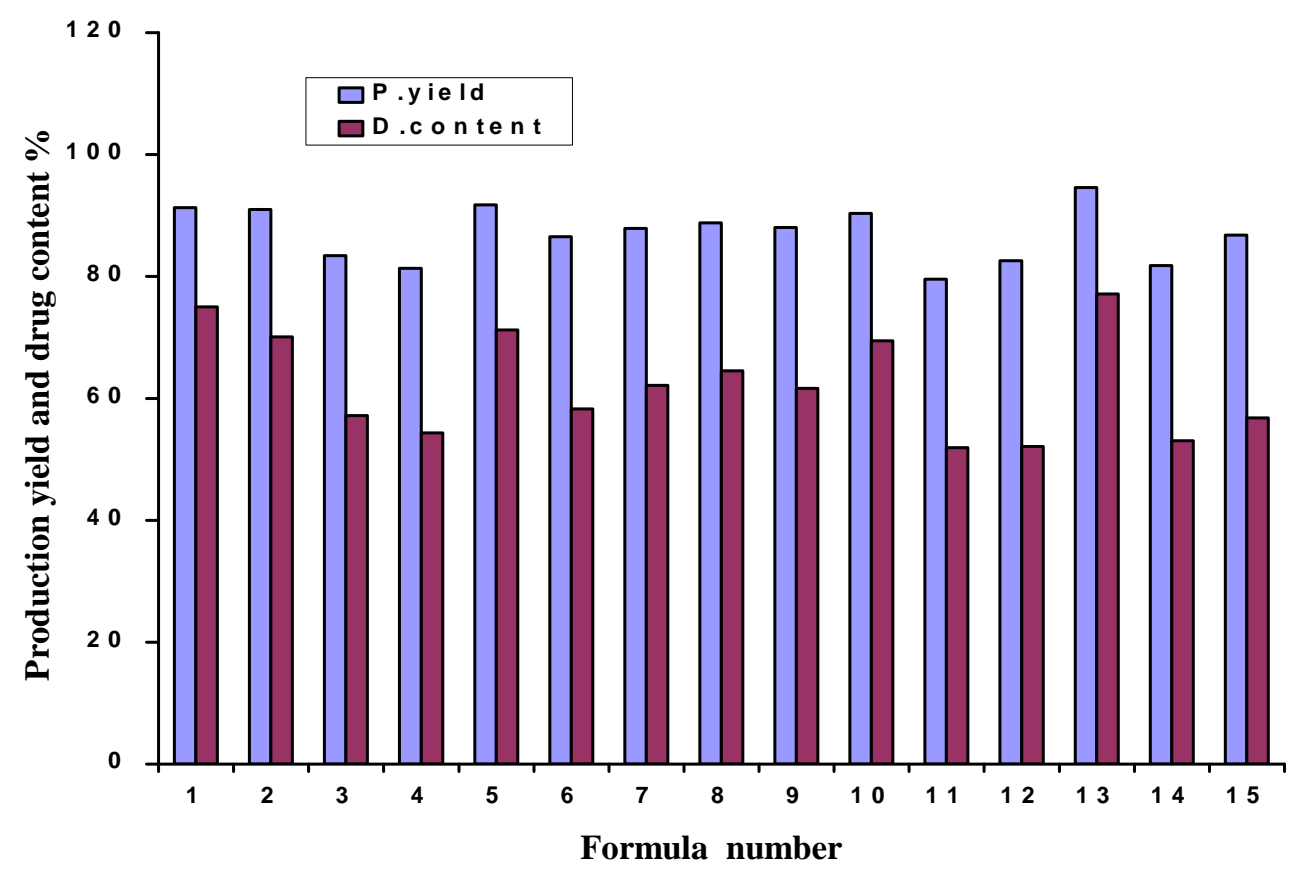

Fig. 1: Histogram showing the production yield and drug content of ketorolac tromethamine cellulose acetate butyrate microspheres.
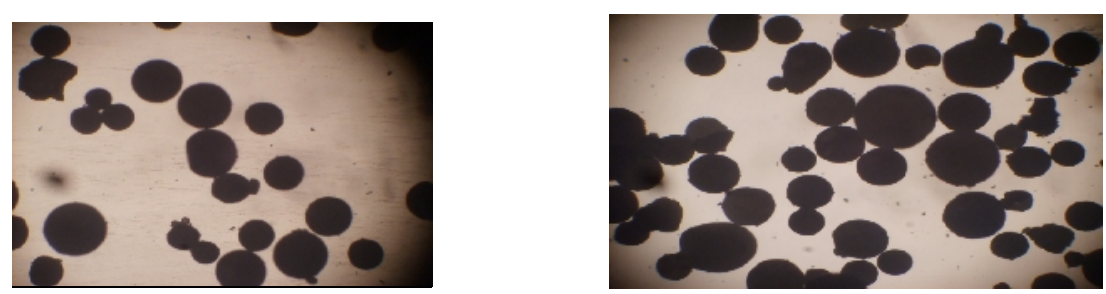

Fig. 2: Optical micrograph of ketorolac tromethamine - CAB microspheres, F3 and F14. 
In this study evaporation process performed at room temperature because lower and higher temperature produce larger spheres whereas intermediate temperatures produced smaller spheres. The same finding was obtained by the work done by Yang et al. $^{24}$. Also higher temperature resulted in highly porous skin and core due to rapid solvent evaporation $^{25}$.

\section{Photo-micrographs of ketorolac trome- thamine-cellulose acetate butyrate micro- particles}

Photo-microscopic technique was used to give as a clear picture about the shape and the surface of the prepared ketorolac tromethamine cellulose acetate butyrate microspheres. Also, this technique gave us an idea about the efficiency of the emulsion-solvent evaporation process.

Figure 2 illustrates the results of photomicrographs. All the prepared ketorolac tromethamine cellulose acetate butyrate microspheres were spherical in shape with smooth surface except formulae F12 and F13 which were semispherical with irregular surface. The sizes of the tested formulae were different in diameters.

\section{Thermal gravimetric analysis (TGA)}

In order to shed a light on the possibility of solid state changes of ketorolac tromethamine with Cellulose Acetate Butyrate, TGA were performed on the drug polymer systems and their physical mixtures, as well as, individual components as shown in table 4 and figure 3.

The TGA scan of ketorolac tromethamine alone (Fig. 3, curve A), showed two endothermic indicative minima, the first at $156.6^{\circ} \mathrm{C}$ indicated dehydration process of ketorolac tromethamine salt, while the second at $166.22^{\circ} \mathrm{C}$ indicated it's melting point, $\Delta \mathrm{H}$ values of $-196.37 \mathrm{~J} / \mathrm{g}$ at $10^{\circ} \mathrm{C} / \mathrm{min}$. (Table 4).

The TGA tracing of $\mathrm{CAB}$ showed broad shallow peaks at about $227^{\circ} \mathrm{C}$.

Upon scanning the TGA thermogram of ketorolac tromethamine-CAB physical mixture with drug to polymer ratio 1:1, it was clear that the characteristic endothermic peaks of the drug were seen at 156.17 and $166.56^{\circ} \mathrm{C}$ with $\Delta \mathrm{H}$ value $-376.8 \mathrm{~J} / \mathrm{g}$, indicating that there is no change on the drug in its Cellulose Acetate
Butyrate physical mixture system. However the TGA thermogram of ketorolac tromethamineCellulose Acetate Butyrate microparticles revealed a reduction in the value of endothermic peak of the drug to 152.05 and $163.99^{\circ} \mathrm{C}$ with a pronounced reduction in the $\Delta \mathrm{H}$ value to $-129.09 \mathrm{~J} / \mathrm{g}$ (Table 4 and Fig. 3, curve D).

The characteristic endothermic peaks of ketorolac tromethamine in its-polymer microparticles reduced in its intensity, shifted to lower temperatures and lost its sharpened distinct appearance. Also the drug exhibited lower values of $\Delta \mathrm{H}$ in the prepared microparticles with the tested polymers, indicating that most of the drug was molecularly dispersed within the microparticles ${ }^{26}$.

The appearance of melting peak of the drug in the prepared microparticles signified that the amount of polymers in these systems wasn't enough (drug-polymer ratio 1:1) to complete transformation of the drug to the amorphous form. TGA thermograms revealed that no notable thermal interaction occurred between the drug and the polymers used in this work.

\section{In-vitro release of ketorolac tromethamine capsules}

Figures 4-6 show the in-vitro release of ketorolac tromethamine from their capsules containing formulae from F1 to F15. The maximum and minimum in-vitro release after 8 hrs of dissolution were found to be equal to $100 \%$ and $82.31 \%$.

Figure 4 shows the in-vitro release of ketorolac tromethamine from their capsules containing formulae from F1-F4 using constant drug: polymer ratio 1:1 (X2) with variable span $80,1 \%$ for $\mathrm{F} 2 ; 1.5 \%$ for $\mathrm{F} 1$ and $\mathrm{F} 4 ; 2 \%$ for $\mathrm{F} 3$ (X3), and the variable speeds, $500 \mathrm{rpm}$ for $\mathrm{F} 1$; $700 \mathrm{rpm}$ for F2 and F3; $900 \mathrm{rpm}$ for F4 (X1). The maximum and minimum percent released were observed to be $19.24 \%$ and $13.9 \%$ at the end of two hours (Y1). The maximum and the minimum in-vitro release after four hours (Y2) of dissolution were found to be equal $88.35 \%$ and $72.65 \%$, respectively. After eight hours of dissolution (Y3) the maximum and minimum in-vitro release was found to be equal to $100 \%$ and $92.36 \%$, respectively. 
Table 4: Endothermic peaks and $\Delta \mathrm{H}$ values of ketorolac tromethamine- CAB microsphere (1:1 drugpolymer ratio) as well as the corresponding physical mixtures compared with the individual components.

\begin{tabular}{|l|c|c|c||}
\hline \multicolumn{1}{|c|}{ Samples } & \multicolumn{2}{|c|}{ Endothermic peaks $\left({ }^{\circ} \mathrm{C}\right)$} & $\Delta \mathrm{H}(\mathrm{Joule} / \mathrm{g})$ \\
\hline Drug alone & 156.6 & 166.22 & -196.37 \\
\hline Cellulose Acetate Butyrate & \multicolumn{2}{|c|}{227} & -25.64 \\
\hline Drug- CAB physical mixture (1:1) & 156.17 & 166.56 & -376.8 \\
\hline Drug-CAB microparticles (1:1) & 152.05 & 163.99 & -129.09 \\
\hline
\end{tabular}

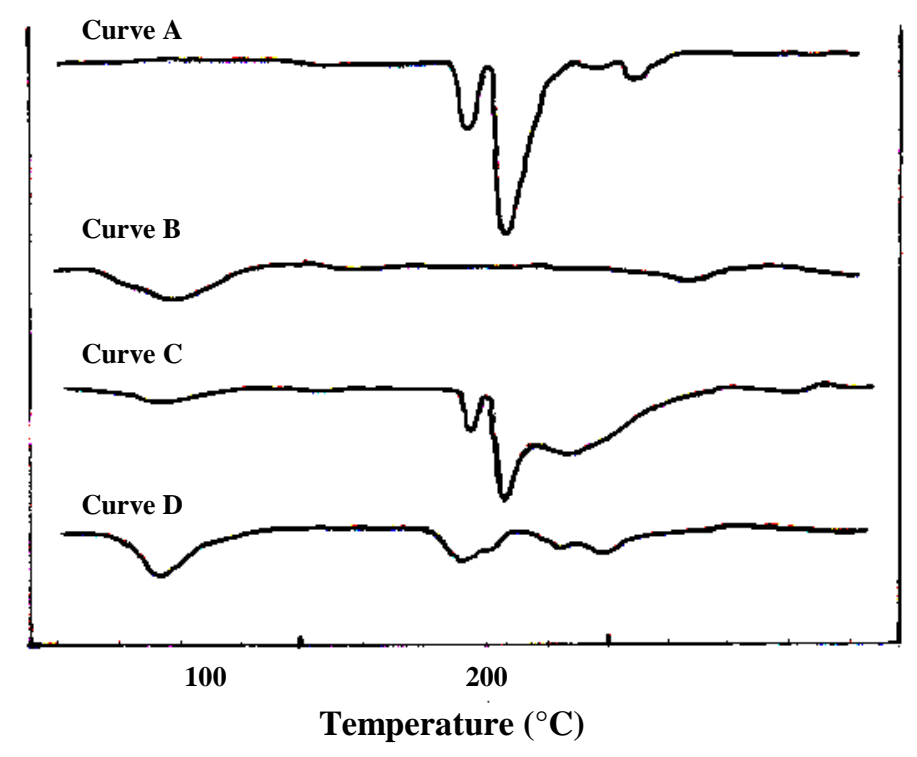

Fig. 3: TGA thermograms of ketorolac tromethamine with $\mathrm{CAB}$ at scanning speed of $10^{\circ} \mathrm{C} / \mathrm{min} .: \mathrm{A}$, Drug alone; B, CAB; C, Ketorolac tromethamine-CAB physical mixture (1:1) and D, Ketorolac tromethamine-CAB microparticles $(1: 1)$.

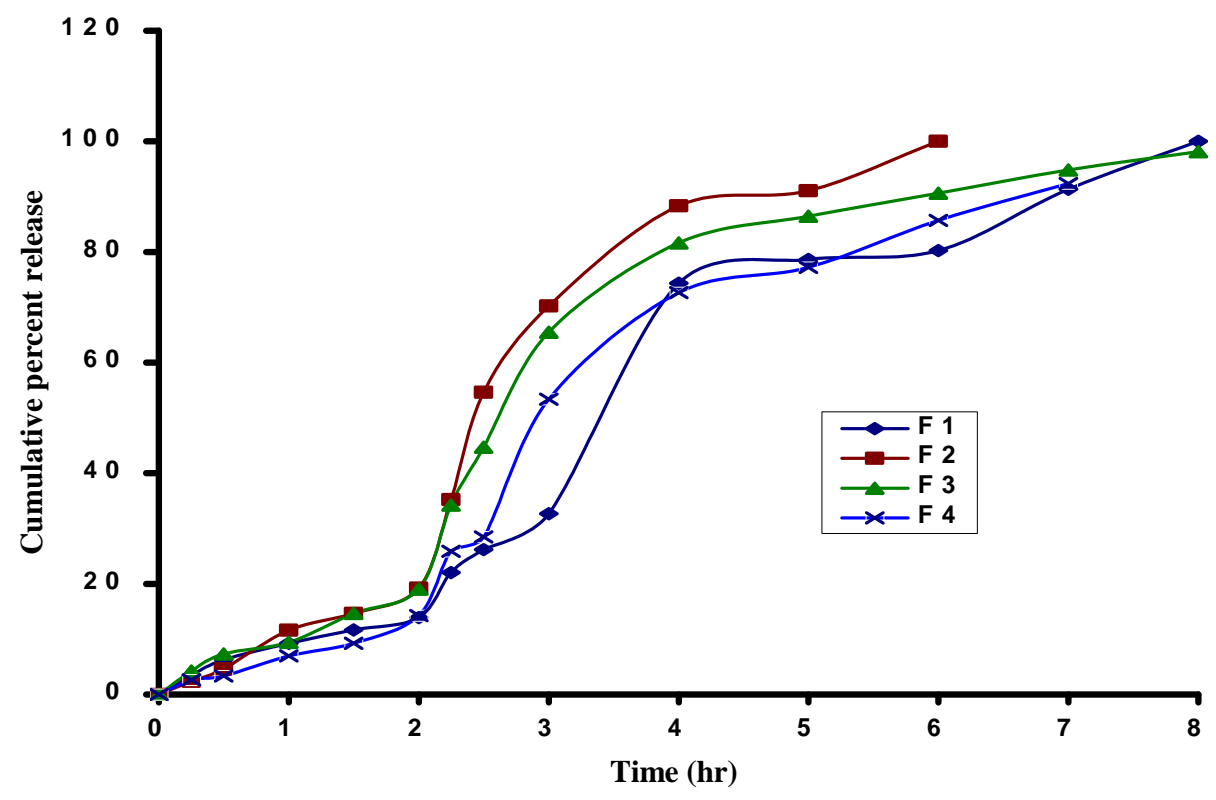

Fig. 4: In-vitro release of ketorolac tromethamine capsules containing drug : polymer ratio 1:1. 
Similar finding obtained by Abd El-Aziz who studied the in-vitro release of diclofenac sodium microspheres from their capsule ${ }^{10}$.

The investigated formulae containing ketorolac tromethamine capsules (F1-F4) can be arranged, in descending order, concerning the in-vitro release within 8 hrs as follows: F4 $>\mathrm{F} 3>\mathrm{F} 1>\mathrm{F} 2$, respectively.

Figure 5 shows the in-vitro release of ketorolac tromethamine from their capsules containing formulae F5-F11 using drugpolymer ratio 1:2 (X2) with variable span 80, $1 \%$ for $\mathrm{F} 5$ and $\mathrm{F} 10 ; 1.5 \%$ for $\mathrm{F} 7, \mathrm{~F} 8$ and $\mathrm{F} 9$; $2 \%$ for F6 and F11 (X3), and also variable speed, 500 rpm for F5 and F6; 700 rpm for F7, F8 and F9; 900 rpm for F10 and F11 (X1).

The maximum and minimum percent released were observed to be $17.02 \%$ and $11.52 \%$ at the end of two hours (Y1). The maximum and minimum in-vitro release after four hours of dissolution (Y2) were found to be equal $72.14 \%$ and $43.69 \%$. Lastly, the maximum and the minimum in-vitro release after eight hours of dissolution (Y3) were found to be equal $100 \%$ and $82.90 \%$.

The investigated formulae containing ketorolac tromethamine capsules (F5-F11) can be arranged, in descending order, concerning the in-vitro release within 8 hrs dissolution as follows: F6 > F11 > F8 > F7 > F9 > F5 > F10, respectively.
Figure 6 shows the in-vitro release of ketorolac tromethamine from their capsules containing formulate F12-F15 using constant drug-polymer ratio 1:3 (X2) with variable span 80, $1 \%$ for $\mathrm{F} 13 ; 1.5 \%$ for $\mathrm{F} 12$ and $\mathrm{F} 15 ; 2 \%$ for F14 (X3), and also variable speed, $500 \mathrm{rpm}$ for F12; $700 \mathrm{rpm}$ for F13 and F14; $900 \mathrm{rpm}$ for F15 (X1). The maximum and minimum percent released were observed to be 13.75 and $11.95 \%$ after the end of two hours (Y1). The maximum and minimum in-vitro release after four hours (Y2) of dissolution were found to be equal 66.78 and 40.66. Lastly, the maximum and minimum in-vitro release after eight hours of dissolution (Y3) were found to be equal $97.90 \%$ and $82.31 \%$.

The investigated formulae containing ketorolac tromethamine capsules (F12-F15) can be arranged, in descending order, concerning the in-vitro release within $8 \mathrm{hrs}$ dissolution, as follows: $\mathrm{F} 14>\mathrm{F} 12>\mathrm{F} 15>$ F13, respectively.

The investigated formulae containing ketorolac tromethamine capsules (F1-F15) can be arranged, in ascending order, regarding the in-vitro release within two hours dissolution (Y1), as follows: F11 (8.87\%), F6 (11.52\%), F12 (11.95\%), F8 (12.78\%), F11 (12.87\%), F9 (13.02\%), F13 (13.06\%), F14 (13.25\%), F15 (13.75\%), F1 (13.90\%), F5 (14.24\%), F7 $(14.25 \%)$, F4 (14.25\%), F13 (19.04\%), F2 (19.24\%), respectively.

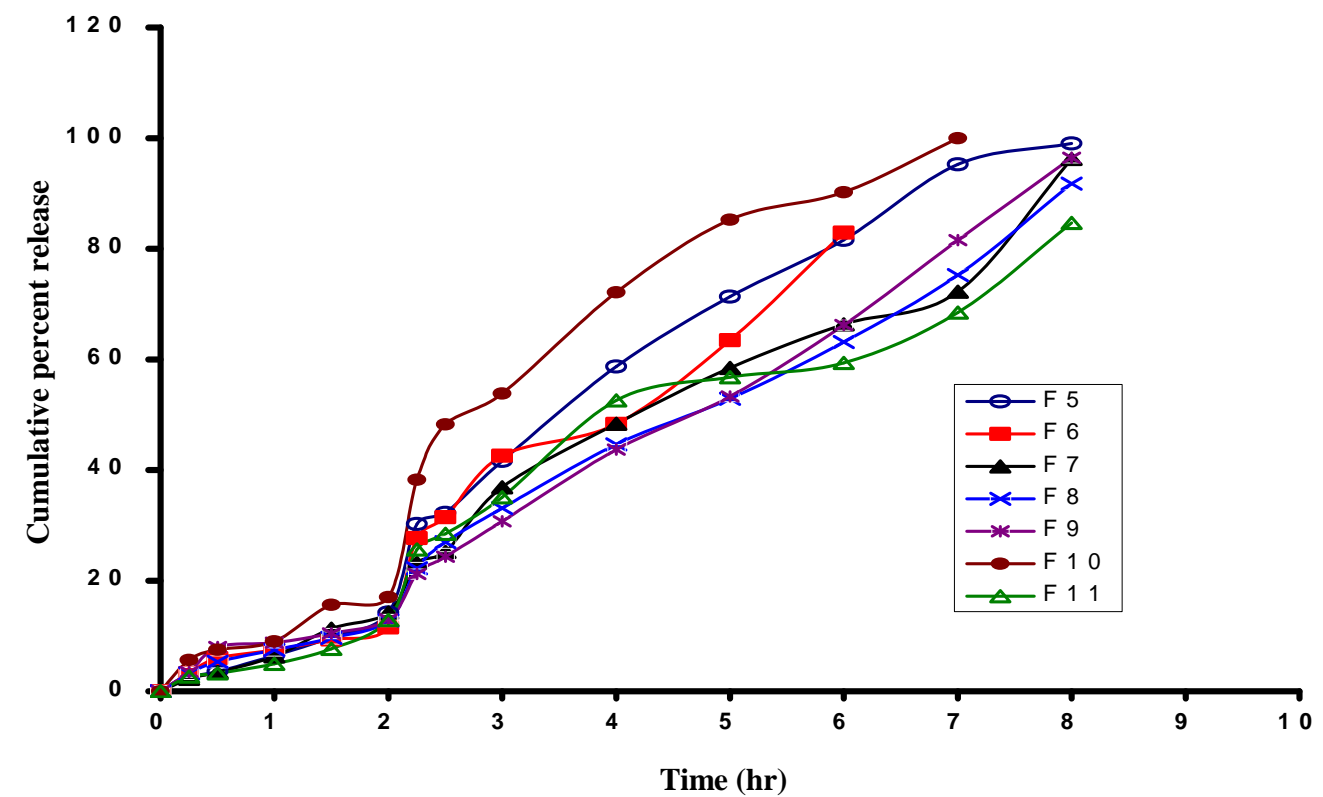

Fig. 5: In-vitro release of ketorolac tromethamine capsule containing drug : polymer ratio 1:2. 


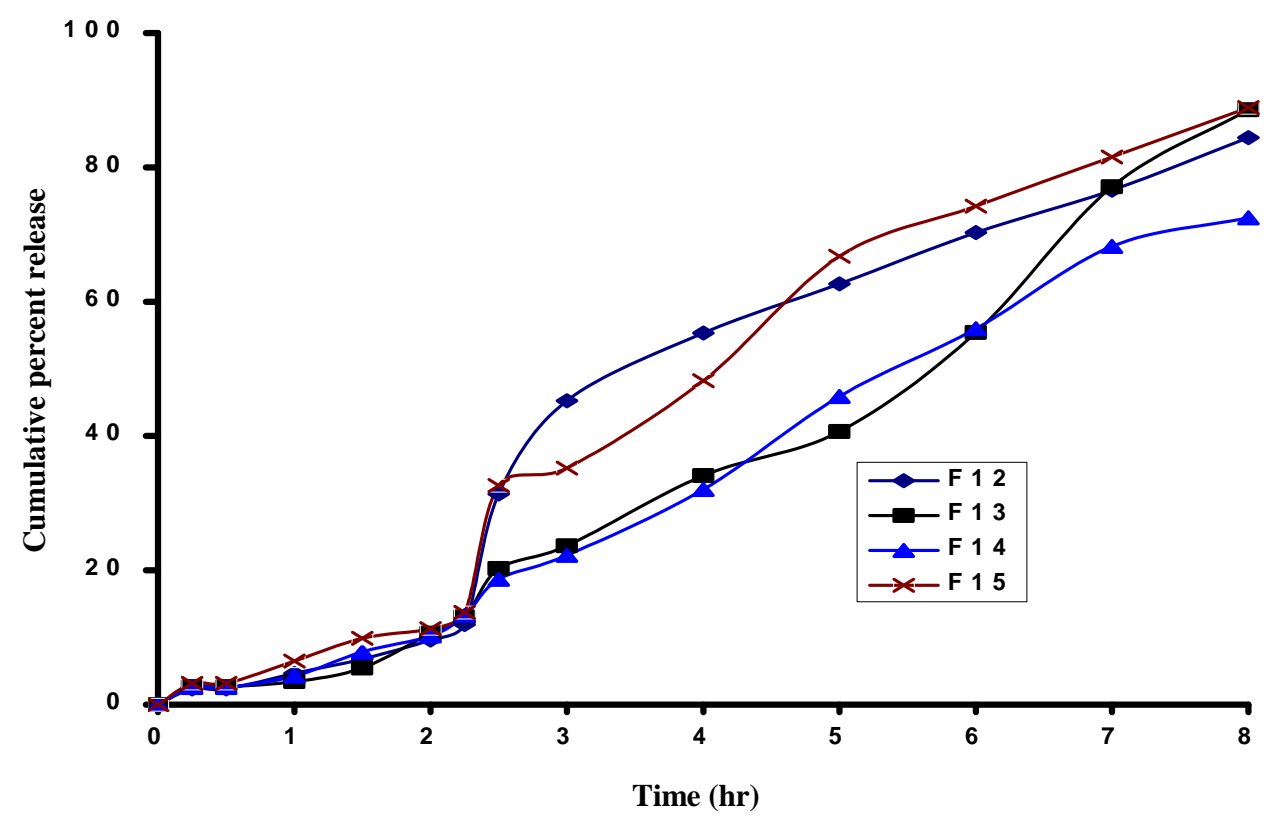

Fig. 6: In-vitro release of ketorolac tromethamine capsules containing drug : polymer ratio 1:3.

The investigated formulae containing ketorolac tromethamine capsules (F1-F15) can be arranged, in ascending order, regarding the in-vitro release within four hours dissolution (Y2), as follows: F13 (40.66\%), F9 (43.69\%), F8 (44.63\%), F14 (45.89\%), F6 (48.33\%), F7 $(48.35 \%)$, F11 (52.58\%), F5 (58.69\%), F12 $(62.65 \%)$, F15 (66.78\%), F10 (72.14\%), F4 $(72.65 \%)$, F1 $(74.34 \%)$, F3 $(81.65 \%)$, F2 $(88.35 \%)$, respectively.

The investigated formulae containing ketorolac tromethamine (F1-F15) be arranged, in ascending order, regarding the in-vitro release within eight hours dissolution (Y3), as follows: F14 (82.31\%), F6 (82.90\%), F11 (84.69\%), F12 (89.05\%), F15 (90.18\%), F8 (91.78\%), F4 (92.36\%), F7 $(96.25 \%)$, F9 (96.45\%), F13 (97.90\%)a, F3 (98.15\%), F2 $(100 \%), \quad F 1 \quad(100 \%)$ and F10 (100\%), respectively.

The investigated formula containing ketorolac tromethamine can be arranged in descending order concerning production yield, drug content, mean particle size and the invitro release as follows: F13, F5, F1, F2, F8, F6, F7, F12, F9, F14, F10, F3, F15, F11 and F4 the results represented in table 5 .

\section{Kinetics of the in-vitro release of ketorolac tromethamine capsules}

The kinetic treatment was done by plotting the time in hours versus the cumulative percent release of ketorolac tromethamine for zeroorder; by plotting the time versus log percent of ketorolac tromethamine retained for first-order; by plotting the time versus the reciprocal of the percent of ketorolac tromethamine retained for second-order; by plotting the time versus cup root of KT, release for Hixson-Crowell cup root low and by plotting time versus percent of KT release according to Baker-Lansdale equation. The kinetic treatment for Higuchi diffusion model was calculated by plotting the square root of time in hours versus the cumulative percent of ketorolac tromethamine release.

In calculating the kinetic parameters for each order or system, the intercept, the slope, the correlation coefficient $(r)$, the specific rate constant and the half-life were obtained in table 6 . Table 7 represents the calculated correlation coefficients for each order or system employed.

It can be observed that the order of release for formulae: F1, F2, F5, F6, F7, F8, F9, F11, $\mathrm{F} 13$ and F14 were found to follow zero order with $\mathrm{t}_{1 / 2} 3.360,2.285,3.576,3.537,4.189$, $4.362,4.145, \quad 4.569, \quad 3.789$ and 4.489 respectively. While formulae F12 and F15 were found to obeyed first order kinetic with $t_{1 / 2}$ 2.377 and 2.121. While formulae F3, F4 and F10 were found to be based on Hixon-Crowell Cup root law with $\mathrm{t}_{1 / 2} 2.046,2.271$ and 2.071, respectively. 
Table 5: Rank order of ketorolac tromethamine-CAB microspheres concerning production yield, drug content, mean particle size and the in-vitro release from capsules.

\begin{tabular}{|c|c|c|c|c|c|c|}
\hline \multirow[b]{2}{*}{$\begin{array}{c}\text { Formula } \\
\text { No. }\end{array}$} & \multirow[b]{2}{*}{$\begin{array}{l}\text { Production } \\
\text { yield }\end{array}$} & \multirow[b]{2}{*}{$\begin{array}{c}\text { Drug } \\
\text { content }\end{array}$} & \multirow{2}{*}{$\begin{array}{c}\text { Mean } \\
\text { particle } \\
\text { size }\end{array}$} & \multirow[b]{2}{*}{$\begin{array}{l}\text { In-vitro } \\
\text { release }\end{array}$} & \multicolumn{2}{|c|}{ Rank order } \\
\hline & & & & & Total & C.R.O \\
\hline F1 & 3 & 2 & 1 & 12 & 18 & 11 \\
\hline F2 & 4 & 4 & 5 & 11 & 24 & 10 \\
\hline F3 & 11 & 10 & 7 & 14 & 42 & 4 \\
\hline $\mathrm{F} 4$ & 14 & 12 & 12 & 10 & 48 & 1 \\
\hline F5 & 2 & 3 & 4 & 9 & 18 & 11 \\
\hline F6 & 10 & 9 & 3 & 2 & 24 & 10 \\
\hline F7 & 8 & 6 & 9 & 6 & 29 & 9 \\
\hline F8 & 5 & 5 & 10 & 4 & 24 & 10 \\
\hline F9 & 7 & 7 & 11 & 7 & 32 & 7 \\
\hline F10 & 6 & 8 & 13 & 13 & 40 & 5 \\
\hline $\bar{F} 11$ & 15 & 15 & 14 & 3 & 47 & 2 \\
\hline F12 & 12 & 14 & 2 & 2 & 30 & 8 \\
\hline F13 & 1 & 1 & 6 & 5 & 13 & 12 \\
\hline F14 & 13 & 13 & 8 & 1 & 35 & 6 \\
\hline F15 & 9 & 11 & 15 & 8 & 43 & 3 \\
\hline
\end{tabular}

Table 6: Kinetic parameters for the in-vitro release of ketorolac tromethamine - CAB capsules according to the suitable order or system.

\begin{tabular}{|c|c|c|c|c|c|c||}
\hline $\begin{array}{c}\text { Formula } \\
\text { No. }\end{array}$ & $\mathrm{I}$ & $\mathrm{S}$ & $\mathrm{R}$ & $\mathrm{K}$ & $\mathrm{T}_{1 / 2}$ & Order \\
\hline $\mathrm{F} 1$ & 5.891 & 14.87 & 0.964 & 14.87 & 3.360 & Zero \\
\hline $\mathrm{F} 2$ & 8.907 & 21.87 & 0.959 & 21.87 & 2.285 & Zero \\
\hline F3 & 0.250 & 0.467 & 0.984 & 0.467 & 2.046 & $\mathrm{HC}$ \\
\hline F4 & 0.340 & 0.420 & 0.982 & 0.420 & 2.271 & $\mathrm{HC}$ \\
\hline F5 & 4.199 & 13.98 & 0.988 & 13.98 & 3.576 & Zero \\
\hline F6 & 5.618 & 14.13 & 0.980 & 14.13 & 3.537 & Zero \\
\hline F7 & 3.739 & 11.93 & 0.991 & 11.93 & 4.189 & Zero \\
\hline F8 & 3.413 & 11.64 & 0.994 & 11.46 & 4.362 & Zero \\
\hline F9 & 4.431 & 12.05 & 0.993 & 12.05 & 4.145 & Zero \\
\hline F10 & 0.279 & 0.461 & 0.980 & 0.461 & 2.071 & HC \\
\hline F11 & 1.996 & 10.94 & 0.982 & 10.94 & 4.569 & Zero \\
\hline F12 & 2.088 & 0.126 & 0.987 & 0.291 & 2.377 & First \\
\hline F13 & 7.269 & 13.19 & 0.992 & 13.19 & 3.789 & Zero \\
\hline F14 & 3.288 & 11.13 & 0.992 & 11.13 & 4.489 & Zero \\
\hline F15 & 2.114 & 0.141 & 0.998 & 0.326 & 2.121 & First \\
\hline
\end{tabular}

$\mathrm{I}=$ Intercept

$$
\mathrm{S}=\text { Slope }
$$

$\mathrm{R}=$ Correlation Coefficient

$\mathrm{K}=$ specific rate constant $\left(\mathrm{hr}^{-1}\right)$ 
Table 7: The calculated correlation coefficient for the in-vitro release of ketorolac tromethamine capsules.

\begin{tabular}{|c|c|c|c|c|c|c|}
\hline $\begin{array}{c}\text { Formula } \\
\text { No. }\end{array}$ & Zero & First & Second & Diffusion & H-C & B-L \\
\hline F1 & 0.964 & 0.957 & 0.877 & 0.935 & 0.963 & 0.939 \\
\hline F2 & 0.959 & 0.948 & 0.894 & 0.932 & 0.957 & 0.923 \\
\hline F3 & 0.944 & 0.981 & 0.796 & 0.958 & 0.984 & 0.979 \\
\hline F4 & 0.972 & 0.975 & 0.882 & 0.953 & 0.982 & 0.959 \\
\hline F5 & 0.988 & 0.923 & 0.669 & 0.972 & 0.976 & 0.936 \\
\hline F6 & 0.980 & 0.944 & 0.848 & 0.940 & 0.964 & 0.892 \\
\hline F7 & 0.991 & 0.879 & 0.651 & 0.968 & 0.945 & 0.859 \\
\hline F8 & 0.994 & 0.928 & 0.756 & 0.964 & 0.965 & 0.891 \\
\hline F9 & 0.993 & 0.888 & 0.671 & 0.953 & 0.946 & 0.872 \\
\hline F10 & 0.972 & 0.973 & 0.907 & 0.952 & 0.980 & 0.953 \\
\hline F11 & 0.982 & 0.968 & 0.868 & 0.970 & 0.981 & 0.934 \\
\hline F12 & 0.954 & 0.987 & 0.936 & 0.962 & 0.983 & 0.981 \\
\hline F13 & 0.992 & 0.901 & 0.668 & 0.956 & 0.956 & 0.987 \\
\hline F14 & 0.992 & 0.982 & 0.926 & 0.968 & 0.990 & 0.953 \\
\hline F15 & 0.968 & 0.988 & 0.940 & 0.967 & 0.987 & 0.976 \\
\hline \hline
\end{tabular}

\section{Conclusion}

Ketorolac tromethamine was successfully encapsulated into cellulose acetate butyrate using emulsion solvent evaporation method. A Box-Behnken design was selected for formulating ketorolac tromethamine microspheres with revolution per minute (X1), drug-polymer ratio (X2) and span 80 percent (X3) as independent variables. Three levels of the independent variables were used which equal to $-1,0$ and +1 for the above design. The values of the corresponding variable are 500, 700 and $900 \mathrm{rpm}$ for the machine speed; $1: 1$, $1: 2$ and $1: 3$ for drug-polymer ratio and $1 \%$, $1.5 \%$ and $2 \%(\mathrm{w} / \mathrm{w})$ for span 80 percent. All the prepared ketorolac tromethamine cellulose acetate butyrate microspheres were spherical in shape with smooth surface except formulae F12 and F13 which were semispherical with irregular surface. The investigated formulae containing ketorolac tromethamine can be arranged in descending order concerning production yield, drug content, mean particle size and the in-vitro release as follows: F13, F5, F1, F2, F8, F6, F7, F12, F9, F14, F10, F3, $\mathrm{F} 15, \mathrm{~F} 11$ and F4. The order of release for ketorolac tromethamine- $\mathrm{CAB}$ were found to follow different kinetic orders or systems and no one kinetic order can explain the release of ketorolac tromethamine-CAB capsules.

\section{REFERENCES}

1- Martindale, "The Extra Pharmacopoeia", $34^{\text {th }}$ Ed., Renolds J.E.F., (ed.), The Pharmaceutical Press, London, 2005, p. 52.

2- D. Colin, In: "Therapeutic Drugs", $2^{\text {nd }}$ Ed., 2, 1999, p. 21.

3- S. K. Sahoo, A. A. Mallick, B. B. Barik and P. C. Senapati, "Preparation and invitro evaluation of ethylcellulose microspheres containing stavudine by the double emulsion method", Pharmazie, 62, 117-121 (2007).

4- K. P. R. Chowdary, R. N. Koteshwara and K. Malathi, "Ethyl cellulose microspheres of glipizide: characterization, in-vitro and in-vivo evaluation", Ind. J. Pharm. Sci., 66, 412-416 (2004).

5- A. Kramar and F. Vrecer, "Statistical optimisation of diclofenac sustained release pellets coated with polymethacrylic films", Int. J. Pharm., 256, 43-52 (2003).

6- K. Kyoko, Q. Chun-Jun, M. Yoshifumi and K. Susmu, "Preparation of chitosan microparticles by water-in-vegetable oil emulsion coalescence technique", Reactive and Functional Polymers, 62, 7783 (2005). 
7- F. Giovanni, Palmieri, B. Giulia, D. M. Piera and M. Sante, "Microencapsulation of semisolid ketoprofen/polymer microspheres", Int. J. Pharm., 242, 175178 (2002).

8- F. A. Mohammed, "In-vitro and in-vivo studies of aspirin microcapsules obtained by emulsion non solvent addition (ENSA) technique", Assiut University, Third Pharmaceutical Sciences Conference, Assiut, Egypt, 103-113 (2002).

9- E. A. Abd Elaziz, "Preformulation Studies on Controlling The Release of Certain Pharmaceutical Dosage Form(s)", Master Thesis, Al-Azhar University, Cairo, Egypt (2004).

10- N. Kondo, T. Iwao, K.I. Hirai, M. Fukuda, K. Yamanouchi, K. Yokoyama, M. Miyaji, Y. Ishihara, K. Kon, Y. Ogawa and T. Mayumi, "The production of active substance compositions in the form of a solid solution of the active substance in a polymer matrix, and active substance compositions produced by this process", J. Pharm. Sci., 83, 566 (1994).

11- M. M. Ahmed, "The Controlled Release of Some Non-Steroidal Anti-Inflammatory Drugs From Microspheres", Master Thesis Al-Azhar University, Cairo (2006).

12- W. Abd Elaa, "Formulation and Evaluation of Microspheres and Microcapsules Containing Ketoprfen", Master Thesis, Al-Azhar, University, Cairo (2007).

13- T. Higuchi, "Theoretical analysis of rate release of solid drugs dispersed in solid matrices", J. Pharm. Sci., 52, 1145-1149 (1963).

14- R. W. Baker and H. K Lonsdal, In: "Controlled Release of Biologically Active Agents", A. C. Tanquary and R. E. Lacey, (ed), Plenum. Press, New York, 1974, p. 15.

15- W. Hixon and G. H. Crowel, In: "Pharmaceutics of Solid Dosage Forms", Willy, New York (1977).

16- R. Arshady, "Preparation of biodegradable microspheres and microcapsules: 2 . Polylactides and related polyesters", J. Cont. Rel., 17, 1-22 (1991).

17- A. Barkai, Y. V. Pathak and S. Benita, "Polyacrylate (Eudragit retard) microspheres for oral controlled release of nifedipine. I. formulation design and process optimization", Drug Dev. Ind. Pharm., 16, 2057-2075 (1990).

18- P. Sansdrap and A. J. Moes, "Influence of manufacturing parameters on the size characteristics and the release profiles of nifedipine from poly(DL-lactide-coglycolide) microspheres", Int. J. Pharm., 98, 157-164 (1993).

19- Y. Y. Yang, T. S. Chung and N. P. Ng, "Morphology, drug distribution, and invitro release profiles of biodegradable polymeric microspheres containing protein fabricated by double-emulsion solvent extraction/evaporation method", Biomat., 22, 231-241 (2001).

20- T. Mateovic, B. Kriznar, M. Bogataj and A. Mrhar, "The influence of stirring rate on biopharmaceutical properties of Eudragit RS microspheres", J. Microencapsul., 19 (1), 29-36 (2002).

21- Y. Prongpaibul, J. C. Prince and C. W. Whiteworth, "Preparation and evaluation of controlled release indomethacin microspheres", Drug Dev. Ind. Pharm., 10, 1597-1616 (1984).

22- Y-H. E.Lin and R. C. Vasavada, "Studies on microencapsulation of 5-fluorouracil with poly(ortho ester) polymers", J. Microencapsul., 17, 1-11 (2000).

23- S. Haznedar and B. Dortunc, "Preparation and in-vitro evaluation of Eudragit microspheres containing acetazolamide", Int. J. Pharma. 269, 131-140 (2004).

24- Y. Y. Yang, T. S. Chung, X. L. Bai and W. K. Chan, "Effect of preparation conditions on morphology and release profiles of biodegradable polymeric microspheres containing protein fabricated by double-emulsion method", Chem. Eng. Sci., 55, 2223-2236 (2000).

25- T. W. Chung, Y. Y. Hung and Y. Z. Liu, "Effects of the rate of solvent evaporation on the characteristics of drug loaded PLLA and PDLLA microspheres", Int. J. Pharm., 212, 161-169 (2001).

26- A. R. Kulkarni, K. S. Soppimath, T. M. Aminabhavi and W. E. Rudzinski, "Invitro release kinetics of cefadroxil-loaded sodium alginate interpenetrating network beads", Eur. J. Pharm. Biopharm., 51, 127 133 (2001). 